\title{
EVALUATION OF IMMUNIZATION POLICIES FOR PEACEKEEPING MISSIONS
}

\author{
Robert Steffen
}

Institute of Social and Preventive Medicine of the University, Zurich, and United Nations Transition Assistance Group in Namibia

Jack P. Woodall

World Health Organization

Jörg Nagel

Madeleine Desaules

United Nations Transition Assistance Group in Namibia

\begin{abstract}
This article first examines data bases available to assess the risk of vaccine-preventable diseases (VPD). In the second part, immunization recommendations and practices are briefly evaluated in view of the risk of exposure to VPD and of the efficacy and safety of available vaccines.
\end{abstract}

In continuing to assume responsibility for the health of personnel assigned to peacekeeping missions, the United Nations (UN) issued recommendations for immunizations to the contingents of the various nations taking part in the United Nations Transition Assistance Group (UNTAG) in Namibia (10). Authorities in preventive medicine in the countries recruiting UNTAG forces often, however, decided to add or to delete immunizations from the UN list. These variations are recorded in Table 1, along with the UN recommendations. The important differences in immunization programs stem from different sources. Different data may have been used to compare the impact of vaccine-preventable diseases (VPD) with the safety, efficacy, and costs of such immunizations on the individual observer or on the entire peacekeeping force. Legal and social aspects of such intervention may have been influential. Different conclusions may have been derived from the same data bases. In some cases, older textbooks or personal opinion may have been the basis for a decision. 


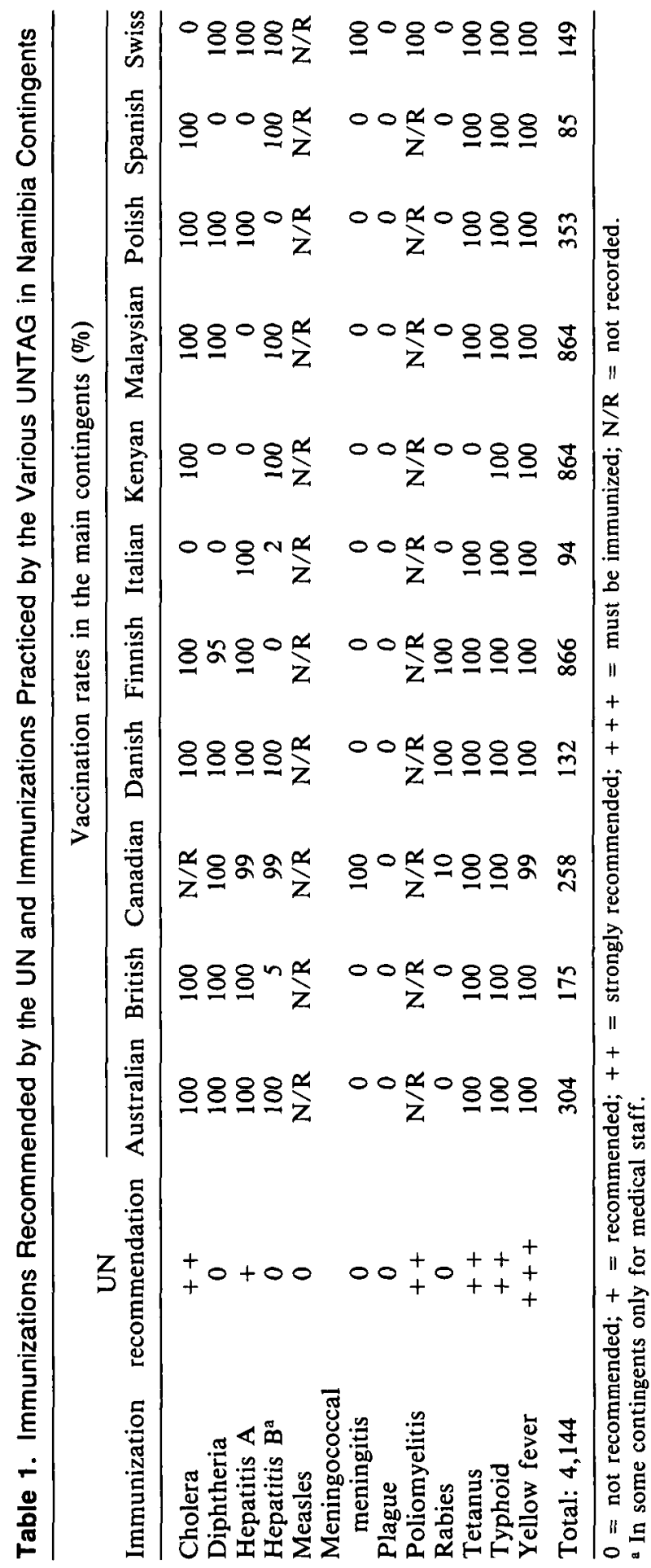




\section{AVAILABLE DATA BASES NEEDED FOR THE DEVELOPMENT OF RECOMMENDATIONS}

\section{Incidence Data on Communicable Diseases}

Ideally, data on the incidence of immunizable diseases within a population that has fulfilled similar duties in the same location should be available. For the UNTAG mission in Namibia, it was possible to analyze data provided by the South African Medical Services, which surveyed all of the armed forces staying in this country.

When such data are not available, incidence and/or prevalence data generated from the autochthonous population in the host country may be substituted. Such data, however, may be misleading. In Namibia, plague is reported to have occurred continuously, with an incidence rate of $8 / 100,000$ in $1987-88(2)$, but not a single case has been observed in the South African Armed Forces. Apparently, all of the cases in the recent years were diagnosed in natives living in specific areas (M. Isaäcson, personal communication). To determine the threat of given infections, the limited data that are available should be analyzed in detail by the epidemiological officers who collected them. Data involving the use of medical services in the host country and claims against sickness funds appear to be less relevant.

If the civil services have been disrupted in the host country for a period of time, data may be unavailable or outdated, particularly if the hygienic conditions have changed greatly since the data were collected. Usually, under such circumstances studying data from neighboring countries that have similar climatic conditions is of only limited usefulness. Unfortunately, for determining the risk of contracting immunizable diseases, epidemiological data from previous $\mathrm{UN}$ or other missions conducted in the same areas after the breakdown of hygiene are usually scarce. The data base of the U.S. Peace Corps is not representative for UN peacekeeping missions (1).

Therefore, it may be worthwhile to consider the risk of immunizable diseases in travelers who have visited Africa, Asia, Central America, or South America. The respective data all show that in susceptible persons hepatitis A occurred more often than typhoid fever and that the incidence of typhoid fever was greater than that of poliomyelitis or of cholera (Table 2) (8). It may be speculated that, except possibly in a very localized epidemic, this sequence of incidence rates will remain constant in all missions, even if the actual rates may vary according to the hygienic conditions.

\section{Host Factors}

Vaccination recommendations must be adapted according to the immunological status of the populations selected for the mission. Some immunizations might be unnecessary for part of the population selected for a mission; for instance, it is unnecessary to administer immunoglobulin to contingents from countries who in their adult populations show prevalence rates close to $100 \%$ for antibodies against hepatitis A. On the other hand, some vaccinations that are considered standard procedure in industrialized countries may not have been given staff members brought up in developing countries. Therefore, it is necessary to review prevalence data for selected infections and data on immunization regulations, including past regulations, in all countries delegating staff to a peacekeeping mission.

One must also be aware of the tasks and particular exposure that various subpopulations will have in the peacekeeping mission. In fulfilling their main tasks of guaranteeing free and fair elections and assisting in the transition to independence, the UNTAG forces were deployed throughout Namibia. Because they traveled frequently, the majority had the same exposure to VPD. However, the risk of hepatitis B was certainly increased in staff who fulfilled medical duties (3). 
Table 2. Morbidity and Mortality of Vaccine-Preventable Diseases in 1 Million Nonimmune Travelers Visiting Developing Countries ${ }^{\mathrm{a}}$

\begin{tabular}{lccc}
\hline Infection & Mortality/month & Incidence/month & $\begin{array}{c}\text { Case fatality } \\
\text { rate (\%) }\end{array}$ \\
\hline $\begin{array}{l}\text { Hepatitis A } \\
\text { Hepatitis B }\end{array} \quad 3,000(-6,000)$ & 0.1 & $3(-6)$ \\
$\quad$ (symptomatic or & & & \\
$\quad$ asymptomatic) & $800(-2,400)$ & 2 & $16(-48)$ \\
Typhoid & 30 & 1 & 0.3 \\
$\quad$ India, N/NW Africa & 300 & 1 & 3 \\
Poliomyelitis & & 20 & 0.2 \\
$\quad$ Symptomatic & 1 & - & $?$ In contacts \\
$\quad$ Asymptomatic & $20(-1,000)$ & 2 & 0.06 \\
\hline
\end{tabular}

No data available for diphtheria, Japanese encephalitis, measles, meningococcal meningitis, rabies, tetanus, tuberculosis, or yellow fever.

a Estimates based on refs. $4 ; 6 ; 8$; and unpublished data.

Table 3. Synopsis of Immunobiologicals for Use in Staff Recruited for Peacekeeping Missions

\begin{tabular}{|c|c|c|c|c|}
\hline Immunization & Application & $\%$ Efficacy & $\begin{array}{l}\text { Effective from } \\
\text { day }^{\mathrm{a}}\end{array}$ & $\begin{array}{l}\text { Duration of } \\
\text { protection }\end{array}$ \\
\hline Cholera & $\mathrm{id} / \mathrm{sc} / \mathrm{im}$ & 50 & P6, R1 & O: $6 \mathrm{mo}$; E: $3-4 \mathrm{mo}$ \\
\hline Diphtheria & im & $80-98$ & 30 & $5(-10)$ yr \\
\hline Hepatitis A (Ig) ${ }^{b}$ & im & 85 & $4-7$ & $4(-6) \mathrm{mo}$ \\
\hline Hepatitis B & im & 90 & $30-60$ & $3-8 \mathrm{yr}$ \\
\hline Japanese encephalitis & im & 90 & 7 & $1-4 \mathrm{yr}$ \\
\hline Measles & sc & $>95$ & 60 & Life(?) \\
\hline \multicolumn{5}{|l|}{ Meningococcal } \\
\hline meningitis & im & $70-90$ & 7 & $1-3 \mathrm{yr}$ \\
\hline Plague & $\mathrm{im}$ & 90 & few & $6 \mathrm{mo}$ \\
\hline Poliomyelitis & $\mathrm{po} / \mathrm{im}$ & $>99$ & 30 & po: $>15 \mathrm{yr} ; \mathrm{im}:>5 \mathrm{yr}$ \\
\hline Rabies & $\mathrm{im} /(\mathrm{id})$ & $>99$ & 7 & $2-3$ yr \\
\hline Tetanus & im & $>99$ & 30 & $10 \mathrm{yr}$ \\
\hline Tuberculosis & ic & $0-80$ & 60 & $10(?) \mathrm{yr}$ \\
\hline Typhoid fever & po/im & 70 & po $15 / \mathrm{im}(?)$ & po: $6(?) \mathrm{yr} ; \mathrm{im}: 3 \mathrm{yr}$ \\
\hline Yellow fever & sc & $>99$ & P10, R1 & $\mathrm{O}: 10 \mathrm{yr} ; \mathrm{E}:>15 \mathrm{yr}$ \\
\hline
\end{tabular}

Abbreviations: $\mathrm{P}=$ primary; $\mathrm{R}=$ revaccination; $\mathrm{O}=$ officially; $\mathrm{E}=$ effectively.

a If more than one dose necessary, number of days following completion of series.

b May possibly provide some protection against hepatitis B and hepatitis non-A, non-B.

\section{Impact of Infection on the Individual and on the Entire Mission}

One has to consider how easily an individual infection can be treated under bad environmental conditions and the nature of the risk of spreading a particular infection throughout the staff. Tetanus has a bad prognosis unless the patient receives optimal and costly therapy, which probably includes evacuation. While tetanus will not affect entire groups of staff, epidemics of meningococcal meningitis may break out in a crowded setting.

\section{Safety and Efficacy of Vaccines and Immunoglobulins}

Vaccines that may be considered for immunization of staff recruited for peacekeeping missions are listed in Table 3. In summary, these vaccines are safe, but the degree of 
efficacy varies among them. Cholera vaccine, in particular, is of uncertain efficacy. The efficacy of Ty2la oral typhoid vaccine appears to be inconsistent, according to the data that have recently been reviewed $(5 ; 6 ; 7)$.

\section{Cost-Benefit Evaluation}

Recently, Wiedermann (9) at the University of Vienna compared the cost of disease and of vaccination by using the formula

$$
Q_{c}=\frac{C_{T h} \cdot R_{m}+C_{L} \cdot R_{L}}{C_{v}+(1-p) C_{T h} \cdot R_{m}+(1-p) C_{L} \cdot R_{L}}
$$

in which $Q_{c}$ stands for the cost-benefit ratio, $C_{T h}$ the cost of therapy, $C_{\nu}$ the cost of vaccination, $R_{m}$ the risk of morbidity, $R_{L}$ the risk of fatality, $C_{L}$ the cost of fatal outcome, and $p$ the protection rate afforded by the vaccine. Of course, the values for $Q_{c}$ vary greatly according to the risks and the costs for different populations and for different risk settings, but a crude estimate is shown in the following two examples.

For cholera, $C_{T h}$ in the field per patient and costs for incapacity to work for half a month may be US $\$ 2,500$; $R_{m}$ may be $4 / 100,000$ per year; $C_{L}$ may be US $\$ 1,000,000$; and $R_{L}$ in such a setting may be $2 \%$ of $R_{m}(4)$, which corresponds to $0.08 / 100,000$ per year. $C_{\nu}$ for two doses per year, including staff and material, may be US $\$ 10 ; p$ is approximately 0.5 . $Q_{c}=0.09$, which is clearly below 1 ; this vaccine is thus not costbeneficial.

For hepatitis $A, C_{T h}$ in the field per patient and costs for incapacity to work for a month may be US $\$ 5,000 ; R_{m}$ may be $600 / 100,000$ per year; $C_{L}$ may be US $\$ 1,000,000$; and $R_{L}$ may be $0.01 \%$ of $R_{m}$, which corresponds to $0.06 / 100,000$ per year. $C_{\nu}$ for three doses per year, including staff and material, may be US $\$ 30 ; p$ has been shown to be approximately $0.85 . Q_{c}=1.002$; this immunization would thus be just cost-beneficial, particularly if we consider that the hygienic conditions may be even less favorable than for travelers (Table 2), from whom the data were derived.

\section{Legal Aspects}

Contrary to an old belief, only a very few countries require cholera vaccination certificates from travelers arriving from endemic areas. As of June 1991, they were only Kenya and Tanzania (Zanzibar and Pemba). Therefore, only staff from these two countries should be vaccinated either before leaving home or at least 6 days before returning home from an assignment in an endemic area. No proof of cholera vaccination is necessary anywhere in the world for staff arriving from nonendemic countries, with the exception of Pemba and Zanzibar (Tanzania).

Egypt, India, and Pakistan consider the whole territory of any country in the yellow fever endemic zone of Africa and South America (10) to be infected with yellow fever and, therefore, demand a yellow fever vaccination certificate from travelers coming from, for example, Kenya. Therefore, staff entering or returning to those three nations from such African or South American countries need to have been vaccinated at least 10 days before arrival.

\section{RECOMMENDATIONS FOR IMMUNIZATIONS IN PEACEKEEPING MISSIONS}

In general, there is a need for uniform policies. Otherwise, members from different contingents may understandably express doubts about the competence or the sense of responsibility of those who have decided about immunization programs. It may be wise to consult the responsible experts in the various countries sending contingents. 


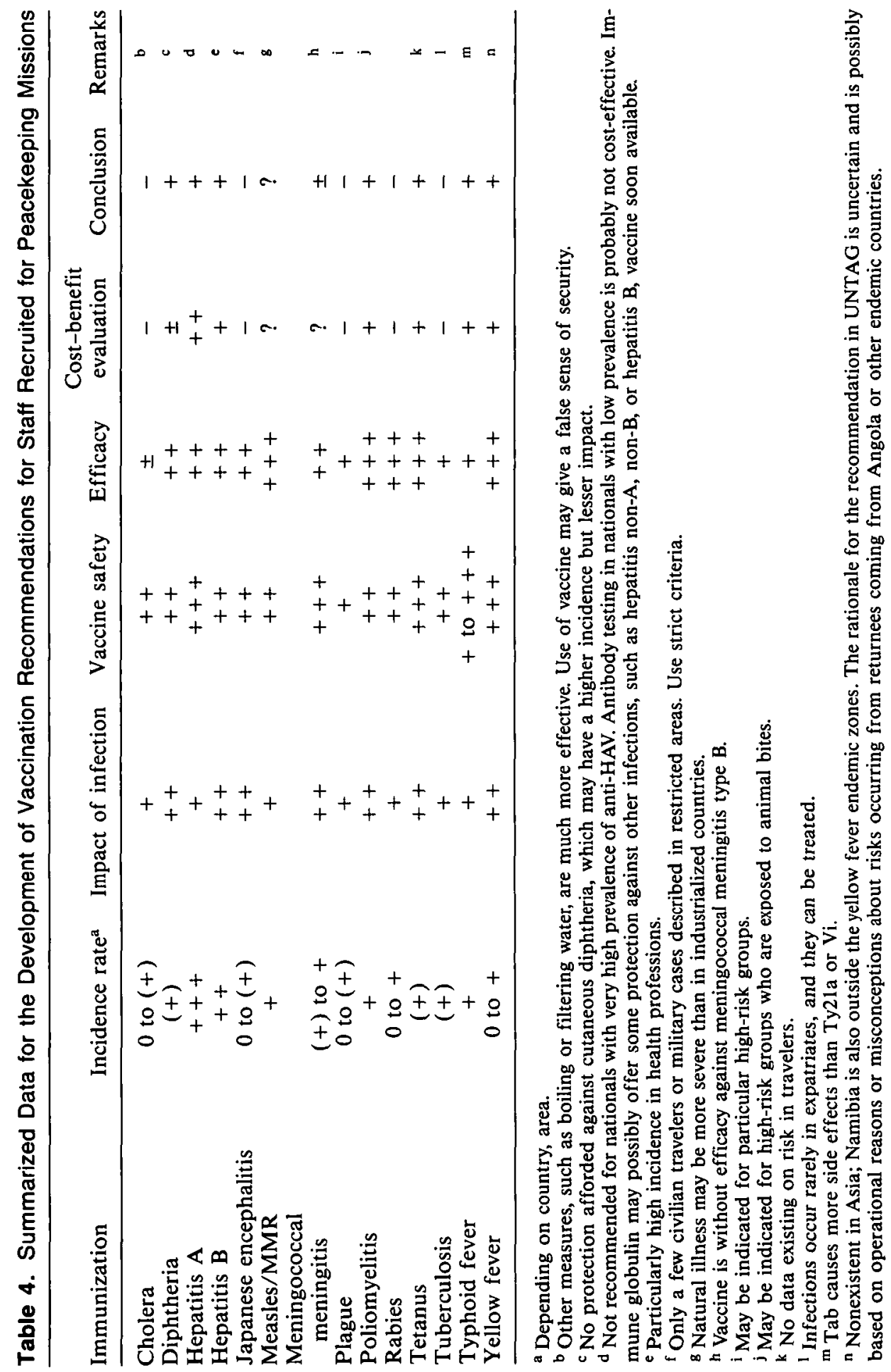


Intelligence on disease risks, generated prior to deployment, is needed to reach a consensus. Continuous surveillance of morbidity and mortality is necessary. It would be helpful if UN headquarters would prescribe a standardized surveillance scheme.

Presumably, there will also be a lack of data for future peacekeeping missions. Current data for the various immunizations are summarized in alphabetical order in Table 4. Staff recruited for peacekeeping missions should be given only the necessary immunizations, and should not be subjected to either the potential adverse reactions or the inconvenience of unnecessary measures. Above all, they should not be immunized against rare infections while being left unprotected against frequent ones, particularly when the latter have a similar fatality rate per case. This discretion might also save costs to the sponsoring organization.

\section{REFERENCES}

1. Bernard, K. W., Graitcer, P. L., van der Vlught, Th., et al. Epidemiological surveillance in Peace Corps volunteers. International Journal of Epidemiology, 1989, 18, 220-26.

2. Department of National Health and Welfare, SWA/Namibia. Health Status Report for SWA/Namibia, April 1, 1987-March 31, 1988, 8.

3. Gamble, K. L., Spence, L., Smith, C. R., \& Keystone, J. S. Hepatitis B in Canadian missionaries serving in developing countries. In R. Steffen, H. O. Lobel, J. Haworth, \& D. J. Bradley (eds.), Proceedings, First Conference on International Travel Medicine. New York: SpringerVerlag, 1989, 270-72.

4. Morger, H., Steffen, R., \& Schär, M. Epidemiology of cholera in travellers, and conclusions for vaccination recommendations. British Medical Journal, 1983, 286, 184-86.

5. Preblud, S. R., Brink, E. W., \& Orenstein, W. A. General use immunizations for travelers. In R. Steffen, H. O. Lobel, J. Haworth, \& D. J. Bradley (eds.), Proceedings, First Conference on International Travel Medicine. New York: Springer-Verlag, 1989, 169-81.

6. Schultz, M. G. Special-use immunobiologics for travelers. In R. Steffen, H. O. Lobel, J. Haworth, \& D. J. Bradley (eds.), Proceedings, First Conference on International Travel Medicine. New York: Springer-Verlag, 1989, 182-202.

7. Woodruff, B. A., Pavia, A. T., \& Blake, P. J. A new look at typhoid vaccination. Journal of the American Medical Association, 1991, 265, 756-59.

8. Steffen, R., \& Raeber, P. A. Vaccination pour les voyages internationaux. World Health Statistics Quarterly, 1989, 42, 85-89.

9. Wiedermann, G. Is vaccination worthwhile before travel? In R. Steffen, H. O. Lobel, J. Haworth, \& D. J. Bradley (eds.), Proceedings, First Conference on International Travel Medicine. New York: Springer-Verlag, 1989, 208-15.

10. United Nations Transition Assistance Group, UN Field Operations Division, unpublished notes for the guidance of military observers on appointment. February 1989.

11. World Health Organization. International travel and health. Vaccination requirements and health advice. Geneva: WHO, 1991. 